Revista de la red interuniversitaria de estudios sobre las literaturas rioplatenses contemporáneas en Francia

13 | 2015

Nuevas experiencias editoriales y literaturas contemporáneas

\title{
El viaje de la ciencia ficción argentina a los confines del espacio interior
}

\section{Martín Felipe Castagnet}

\section{(2) OpenEdition}

\section{Journals}

Edición electrónica

URL: http://journals.openedition.org/lirico/2160

DOI: $10.4000 /$ lirico. 2160

ISSN: 2262-8339

Editor

Réseau interuniversitaire d'étude des littératures contemporaines du Río de la Plata

Referencia electrónica

Martín Felipe Castagnet, «El viaje de la ciencia ficción argentina a los confines del espacio interior », Cuadernos LIRICO [En línea], 13 | 2015, Puesto en línea el 15 diciembre 2015, consultado el 30 abril 2019. URL : http://journals.openedition.org/lirico/2160; DOI : 10.4000/lirico.2160

Este documento fue generado automáticamente el 30 abril 2019.

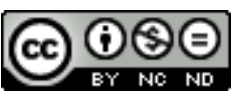

Cuadernos LIRICO está distribuido bajo una Licencia Creative Commons Atribución-NoComercialSinDerivar 4.0 Internacional. 


\title{
El viaje de la ciencia ficción argentina a los confines del espacio interior
}

\author{
Martín Felipe Castagnet
}

\section{Introducción}

El entrecruzamiento crítico entre la ciencia ficción y las políticas editoriales en Argentina ha tenido únicamente la extensión de las notas al pie. Resulta sintomático el por lo demás completo trabajo de Guillermo García sobre la ciencia ficción, presente en el volúmen 10 de la Historia crítica de la literatura argentina (1999) dirigido por Noé Jitrik y Susana Cella : se ha omitido, en las obras mencionadas, informar sobre las editoriales en que se publicaron en primera edición. Paradójicamente, es en la ciencia ficción donde más resulta indispensable analizar el influjo de la industria editorial en el origen y conformación de un género. "More than in any other popular genre, and for that matter more than in most publishing in general, sfs editors and publishers have from the beginning played a highly visible and sometimes controversial role in the evolution and ideology of the field and its readership" (Wolfe 96). Esta imbricación hoy resulta indispensable en tanto enriquece un área habitualmente desolada de los estudios, a la vez que permite iluminar el lado B de la ciencia ficción : el de los verdaderos inventores del género, no de las obras, que son los editores. Así ocurrió desde sus orígenes gracias al célebre editor de Jules Verne, PierreJules Hetzel, uno de los creadores del género de divulgación científica durante la segunda mitad del siglo XIX, y a Hugo Gernsback, el legendario editor de la revista Amazing que dio nombre al género y en cuyo honor fue bautizado el premio Hugo.

2 La ciencia ficción es un género intrínsecamente moderno, jovencísimo ; asimismo, al estar basado en el ideario de la ciencia, que se particulariza en el cambio constante, como género es increíblemente dinámico. El amanecer del nuevo siglo le resulta especialmente fructífero, como señaló Pablo Capanna en un artículo reciente : "No faltan los agoreros que aseguran que, al estar todo inventado, la ciencia ficción se ha quedado sin trabajo. Un 
juicio tan lapidario no vale para la ciencia pero tampoco para la ficción" (2014). Vivimos en los tiempos de la domótica, aquella división de la robótica aplicada ya no a lo industrial sino al hogar, y el espacio está tan lleno de satélites artificiales que ya resultan tan naturales (e indispensables) como las estrellas, pero ya no engendran fantasías siderales sino la esperanza de una buena conexión a internet. La revolución digital sacude los cimientos de la cultura, y la ciencia ficción siempre fue particularmente perceptiva a estos temblores.

3 ¿ Pueden ser las nuevas tecnologías parte de la ciencia ficción ? Antes, la respuesta era un sí rotundo : la distancia entre el invento ficticio y el invento real lo hacía viable, incluso necesario ; ahora se ha perdido la distancia entre el laboratorio y la vida cotidiana. ¿ Si la ciencia es real, puede seguir siendo ciencia-ficción ? La ciencia ficción deja de existir como tal cuando internet se transforma en lo real : no hay máquina más imposible y al mismo tiempo más cotidiana. Una ciencia ficción exitosa es una ciencia ficción condenada a desaparecer o transformarse.

4 Quizás por esta incertidumbre cada vez se publica más ciencia ficción pero sin mencionar el género. Aclararlo resta más de lo que suma : lo cotidiano no puede ser "ciencia ficción", por lo que la etiqueta queda asociada a la imaginería de los cincuenta : los grandes robots resultan pesados y los cohetes parecen de hace mucho tiempo y de una galaxia muy lejana. Por el contrario, a las obras que utilizan los progresos científicos de la época, como ocurre en las novelas de Ian McEwan o Michel Houellebecq, no se las incluye ni editorial ni críticamente en el género. La clonación existe del mismo modo precario en que existían los primeros esbozos de submarinos en la época de Verne : se requiere un salto ficcional prospectivo para explotarlos de modo literario, y eso es en pocas palabras a lo que se dedica el género. Como coletazo del borramiento editorial, cualquier intento de aprehender la ciencia ficción contemporánea debe hacerlo a la par del fantástico, como hermanos siameses que comparten el mismo corazón. Sería pernicioso intentar definir si corresponden a la ciencia ficción, al fantástico o al terror : se enhebran, no se repelen. $\mathrm{Si}$ la ciencia ficción se escindió del fantástico a comienzos de siglo XX, cien años más tarde vuelven a mezclarse y, aunque con claves distintas, deben leerse bajo la misma operación.

5 En estos dilemas se encuentra la ciencia ficción argentina ; como paleontólogos literarios, encontramos vida en lo que ya parecía rocoso y muerto, quizás inexistente. Decía la autorizada voz de Elvio Gandolfo en su estudio preliminar a Los universos vislumbrados (Antología de ciencia ficción argentina) : "La ciencia ficción argentina no existe" (Sánchez 13). La afirmación es paradójica : no se puede hacer una antología de algo inexistente, y si no existe la están inventando desde el libro y su subtítulo. Aun así, Gandolfo no faltaba a la verdad : la ciencia ficción argentina supo brillar de obra en obra sin nunca conformar una tradición. Hoy, a razón de una producción novedosa, la ciencia ficción argentina está cerca de tener su propia constelación en el firmamento literario, pero en el tiempo transcurrido tras ese prólogo ocurrieron cambios tanto en el género como en la edición que afectan al modo en el que circula esa producción.

6 A lo largo de este trabajo analizaremos el viraje hacia un nuevo tipo de ciencia ficción, más introspectiva y borroneada, mediante el análisis de las prácticas editoriales y de figuras referentes en tanto autores y editores como Marcelo Cohen o Hernán Vanoli. 


\section{La periferia del mercado}

7 En Estados Unidos, de donde proceden tanto la invención del género como sus renovaciones, su funcionamiento editorial es extremadamente diferente y por tanto sus trabajos críticos más relevantes funcionan a medias cuando se los quiere leer (y adaptar) desde la Argentina. Entre otras diferencias existe un gremio fuerte (el SWFA, Science Fiction \& Fantasy Writers of America), una temporada de premios (el Nebula y el Hugo, entre otros), un circuito de convenciones (como la Comic-Con) y una tirada varias veces mayor (los diez títulos más vendidos del 2012 iban de los veinticinco mil a los cien mil ejemplares vendidos); la ciencia ficción estadounidense es, en definitiva, un género masivo.

8 La situación en Argentina no puede ser más distinta. En primer lugar, el país se ubica en una posición periférica :

Most English-language sf is written by whites. While some African-American writers produce work that has fantastic or magical elements, this work is not generally grouped with sf or fantasy; it is instead published as and treated by critics as African-American literature. The magical realist elements of Mexican, Native American or Indian subcontinent literatures are also not published or reviewed as speculative literature. (Leonard 253)

9 En consecuencia, gracias a esta definición exclusivista del género se imposibilitó el desarrollo de una ciencia ficción vernácula, ya que ante su origen se le negaba la etiqueta (como muestra, recién este año se traduce El Eternauta al inglés, a casi cincuenta de su publicación). Junto a la etiqueta quedó afuera la masividad del mercado. No resulta casual, por tanto, que la mayor parte de los autores que se mencionan más adelante hayan sido publicados en editoriales independientes; sólo un puñado de autores ha sido publicado en colecciones de grandes grupos editoriales, pero siempre en su sello más prestigioso y menos comercial, como Las chanchas de Félix Bruzzone o Las constelaciones oscuras de Pola Oloixarac publicados en el sello Literatura Random House.

10 Si los términos utilizados para los géneros son discutibles ( $i$ ciencia ficción o ficción científica? ¿fantasy o fantástico?), más discutible aun es la categoría de editoriales independientes. Vale preguntarse: ¿independientes de qué ? Para empezar, no son independientes ni del mercado ni tampoco de las categorías editoriales. Existen cifras que representan, de un modo cabal pero ciertamente inexacto, esta inclusión en el mercado (Saferstein y Vanoli, 2011). ¿Qué sería entonces ser independiente? En principio, no pertenecer al $14 \%$ que supera los 10 millones de pesos de facturación anual y que concentra el $75 \%$ del mercado. Pero tampoco pertenecer al $18,5 \%$ de las medianas empresas, ni siquiera al $16 \%$ de las pequeñas empresas, que facturan desde 1.000 .000 de pesos anuales según los rangos de facturación de la AFIP.

11 En la actualidad, ser independiente significa pertenecer a las microeditoriales que representan hasta el $65 \%$ del total del mercado; de ese sector, el $23 \%$ factura de 1 a 100.000 pesos anuales. En varios casos, editoriales de este tipo como Funesiana o Mancha de Aceite se enorgullecen de las tiradas bajas, al tiempo que construyen instancias de circulación propias. Esta característica es posible gracias al uso masivo de internet, pero una vez que las redes sociales se popularizaron en Argentina no puede decirse que las estrategias de la red sean privilegio de los circuitos alternativos; una prueba es la aparición de un nuevo oficio : el community manager. Si el uso de la red como herramienta 
de difusión no es privilegio de las editoriales independientes, sí cabe decir que la utilizan de modo diferente: al mismo tiempo librería y lugar de socialización. Es posible aventurar que dado lo reducido del mercado particular que prefieren desarrollar las pequeñas y micro editoriales en Argentina, y sobre todo mediante la utilización de las mencionadas redes, en muchas ocasiones los lectores ya saben previamente lo que van a buscar. El libro, indefenso, depende por completo del prestigio del autor para seleccionarlo de los anaqueles ; un lector en busca de ciencia ficción no tiene cómo llegar hasta él. Todas las librerías tienen secciones dedicadas a la ciencia ficción, pero ninguno de los libros de esta nueva camada va a figurar en esos estantes.

\section{El espacio interior}

12 El primer paso para la renovación de la ciencia ficción contemporánea le corresponde, quizás, a Marcelo Cohen. Además de ser autor del género y traductor de Minotauro (y por tanto puente con la primera gran época de la ciencia ficción editada en el Río de la Plata), Cohen fue el responsable de la colección Línea C de la editorial Interzona, en la etapa comandada por Damián Ríos.

Interzona difiere de otras casas editoras porque tuvo varias etapas, en un fenómeno que se ajusta más a los traspasos de las grandes editoriales. Sus primeros editores fueron Edgardo Russo y Damián Ríos, aunque al poco tiempo Russo abandonó el proyecto para fundar otro (El Cuenco de Plata). Luego, cuando Ríos dio un paso al costado en el 2005, se hizo cargo el novelista y periodista Damián Tabarovsky. A fines de 2008, los inversores del emprendimiento pusieron en venta Interzona, y al no encontrar compradores suspendieron las publicaciones, rescindieron los contratos del personal y dejaron de pagar a los autores. Recién en el 2010, el editor Guido Indij compró Interzona y el capital simbólico que la marca proveía. El nombre de esta marca-editorial, ¿ casualmente? proviene del territorio fronterizo, extraño e internacionalista de Naked Lunch de William Burroughs, novela hoy aceptada como parte de la ciencia ficción luego de muchos años de exclusión, precisamente por su uso extraño de los motivos recurrentes del género (extraterrestres, telepatía, objetos parlantes).

Bajo el sello de esta colección de fantástico y ciencia ficción, Interzona publicó Paz de Gene Wolfe, Preparativos de viaje de M. John Harrison, El azogue de China Miéville, August Eschenburg de Steven Millhauser y La maravillosa historia de Peter Schlemihl de Adalbert von Chamisso. El catálogo revela una operación arriesgada para la post crisis del 2001 : introducir en la Argentina traducciones de obras contemporáneas, cuando las editoriales pequeñas suelen traducir libros que ya no pagan derechos.

Hay que explicar que los países latinos quieren volver a decidir sobre sus preferencias, que necesitan traducir porque la lengua no es la misma; muchos de los libros españoles que llegan son difíciles de entender para el lector porque el castellano se ha diversificado de una manera extrema. Además, ya no funciona la utopía de una lengua neutra, porque muchos de los escritores más interesantes escriben en jerga ; y la jerga sólo se puede traducir en jerga. (Enriquez)

La única obra argentina de la colección fue Plop, una novela apocalíptica del fallecido Rafael Pinedo. En su contratapa se lee: "Lejos de los habituales temas de la tecnología moderna, Plop es ciencia rudimentaria y ficción de las ruinas". Ciencia y ficción siguen conformando el aparato paratextual, pero esta vez por separado. Con pocas obras y 
mucho esfuerzo, Línea C ayudó a abatir el estancamiento en el que estaba sumido el género.

16 La decisión de armar una colección específicamente de ciencia ficción y fantástico también fue obra del propio Cohen, "para no caer en la diletancia y porque soy un amante del género" (Enriquez, 2004). Cohen como autor creó un espacio futurista, compuesto por una red de islas interdependientes, que desde el libro de cuentos Los acuáticos llama el Delta Panorámico, "el mundo de las posibilidades de nuestro mundo". No obstante, Cohen explicitó en una entrevista que al armar la colección descubrió que no había tanta buena producción de ciencia ficción contemporánea :

Después de la última oleada renovadora del cyberpunk, hay una gran desorientación. Por otra parte, la ciencia ha progresado tan rápido que es muy difícil pensar en dispositivos que signifiquen algún adelanto. La exploración de aquello que llamamos intimidad, que está constituida por los elementos del paisaje que ha hecho la cultura, está literariamente en una leve crisis. Como si hubiera un cambio de paradigma que no se llega a articular. (Enriquez)

17 Un estudio del tratamiento de la ciencia ficción en la industria editorial argentina debe preguntarse en qué consiste ese cambio de paradigma que, de a poco, comienza a observarse en los últimos años. La respuesta parece provenir de una frase de J. G. Ballard que cita Cohen : "La ciencia ficción tiene que dejar de ocuparse del espacio exterior y el futuro lejano y ocuparse del futuro cercano y el espacio interior".

18 Ese espacio interior está acompañado en la literatura argentina contemporánea por tecnologías acordes: ya no es la nave interespacial, sino la computadora personal. Lo digital era, antes, terreno de la ciencia ficción; hoy lo digital es lo real, pero aún así la ciencia ficción contemporánea encuentra en internet un modo de configurar la construcción de la intimidad y la transmisión de la experiencia. Mario Levrero (un autor habitual del género) escribió en La novela luminosa (su obra más famosa, que no es de género) : "Si me he mudado a vivir en el mundo de la computadora, es porque casi no hay para mí otro mundo posible. ¿ Adónde podría ir, qué otra cosa podría hacer? ¿Qué otra posibilidad hay de un diálogo inteligente? Y afectos. Distantes, distorsionados por las palabras (y aun los sonidos) que los transcriben, están sin embargo allí al alcance de la mano". (Levrero 272)

19 En la contratapa sin firma de No alimenten al troll de Nicolás Mavrakis, publicado por Tamarisco en 2012, se lee: "La continuidad perversa de una novela técnica como un sobreviviente que vuelve perturbado del campo de batalla e intenta mirar lo actual a los ojos". Sólo algunos cuentos de No alimenten al troll poseen elementos del género, aquellos que llevan a que en la contratapa se la denomine como una obra "técnica". Siendo la informática una tecnología que avanza tan rápidamente, $i$ internet pertenece al realismo o a la ciencia ficción ? En determinados casos, el presente de la narración ocurre un paso más adelante del presente. "Lo actual" es el futuro, o la sombra que proyecta el presente sobre el futuro.

20 A su vez, "el campo de batalla" posee una doble entrada. Por un lado, es el soldado que vuelve mudo del campo de batalla, según Benjamin en el ensayo "El narrador". En este caso, la experiencia traumática que no se puede comunicar no es la de la guerra sino la de internet, la nueva tecnología que revela el resentimiento humano desde la figura seminal del troll. Este cinismo concuerda con los lineamientos centrales de la obra del "mismísimo" Michel Houellebecq, tal como se lo menciona en el último cuento, cuya primera novela tiene como título Ampliación del campo de batalla en la versión al castellano 
publicada por Anagrama. La referencia a Houellebecq es particularmente significativa en tanto varias de sus novelas poseen elementos que son tradicionalmente constitutivos de la ciencia ficción, como clonación, ucronías y religiones del futuro, sin que por eso se lo enmarque dentro de ese género ni por el grueso de la crítica ni desde las marcas paratextuales.

21 En "La vida es buena bajo el mar", un cuento publicado en El loro que podía adivinar el futuro, Lamberti escribe una auténtica ciencia ficción argentina que tiene a un psicólogo como protagonista. Unos alienígenas llegan a la Tierra para trabajar como empleados altamente especializados: "encerrados en boxes, escribían en un lenguaje inédito el software de una generación futura de computadoras"; de tanto tratar a los extraterrestres a raíz de la depresión crónica que sufren, el psicólogo se vuelve adicto a una de sus prácticas, semejante a un viaje astral. Ante una pregunta de Walter Lezcano, Lamberti responde : "Si yo quiero cruzar los cuentos con algo, todos trabajan con el tema de la droga e Internet, es decir, Internet como droga” (Lezcano 2012).

22 Internet también es el campo de batalla de Las redes invisibles del ya citado Sebastián Robles, cuyos adelantos fueron publicados en la revista Paco y luego en su totalidad por la reciente editorial Momofuku. El libro retoma la operación de Ítalo Calvino pero con redes sociales ficticias en lugar de urbes: "Las redes sociales hoy en día son espacios de sociabilidad tan importantes y tan ricos como fueron las ciudades hace algunos siglos" (Sáliche, 2014). Por medio de este libro se puede demostrar una hipótesis de Juan Terranova : en la ciencia ficción hay cada vez menos ciencia pero también cada vez menos ficción. Todas las redes sociales del libro, salvo la proverbial excepción, bien podrían existir : sólo falta alguien que las escriba, pero en código.

23 Por un lado, el epígrafe admite cándidamente la influencia de Calvino con exactamente las últimas palabras de Las ciudades invisibles. Con esta operación, el infierno es reemplazado por internet, "que ya existe, se habita todos los días y formamos estando juntos" (Calvino, citado por Robles en epígrafe de su libro). La ficción, específicamente la ficción especulativa, es la manera arriesgada de buscar quién y qué, en medio de internet, no es infierno. Por su parte, la dedicatoria ("Y a mi viejo, por la colección Minotauro") responde a la primera edición de Las ciudades invisibles en castellano, que fue posibilitada por la relación entre Calvino y Aurora Bernárdez, por entonces esposa de Cortázar (publicado por Porrúa tanto en Sudamericana como en Minotauro) y traductora del libro. Pero sobre todo, esta mención responde a la colección completa, cuyo catálogo es la pista de despegue para el género en castellano, para los lectores de entonces y para los escritores de ahora.

\section{La ciencia ficción de la truchez}

24 Momofuku es la segunda editorial de Hernán Vanoli, en compañía de Lola Copacabana, tras la disolución de Tamarisco, fundada en el 2006 por Vanoli, Sonia Budassi, Félix Bruzzone y Violeta Gorodischer. Como muchas otras llamadas "independientes", estas editoriales se caracterizan por el desarrollo de mercados particulares, a través de la ubicación del producto en las llamadas librerías boutique y fomentados a través de las redes sociales y el boca a boca. En este tipo de editoriales es importante destacar el doble rol de escritor y editor (y también, dado que ya no podemos menospreciar el valor de las redes sociales, de community manager). En lo que respecta al mero funcionamiento, y no a la circulación de los libros, no es muy diferente a las editoriales independientes de 
épocas anteriores; en el caso mencionado de Minotauro, Porrúa contrataba el libro, lo traducía, lo corregía, lo llevaba a la imprenta, seguía paso a paso el proceso, decidía las solapas; como firmar la traducción le parecía un exceso, utilizaba diferentes pseudónimos de acuerdo a la calidad.

Vanoli es un caso paradigmático, en tanto autor, editor y crítico, al que se le suma su labor como investigador de la industria editorial, por el cual ya ha sido citado en este trabajo. Vanoli se reconoce deudor de Marcelo Cohen y publicó su primera novela en la tercera etapa de la ya mencionada Interzona. Su primer libro, publicado por Tamarisco, fue Varadero y Habana maravillosa, heredera de la tradicción ballardiana, cuentos donde se abonan los temas que lo obsesionan : la sociedad posindustrial, la adicción a materiales precarios, las aspiraciones de clase, la frustración sexual. Hace algún tiempo, en una charla pública, Cohen propuso la categoría "ciencia ficción de la truchez" para denominar a cierta tradición literaria rioplatense contemporánea : esa ciencia ficción donde las cosas siempre saldrán mal, donde la imaginación tecnológica viene fallada de fábrica, donde el futuro nunca será mejor (Tomas, 2015).

26 Los cuentos de Varadero y Habana maravillosa encuentran una extraña continuidad estilística y temática en un proyecto posterior de Vanoli : Las mellizas del bardo, novela breve publicada por la editorial Clase Turista dentro de la colección Saqueos en Greiscol, en donde el cyborg deja de ser una insinuación para convertirse en su elemento dominante.

Desprolija, plagada de erratas, rabiosa y aliada a un género border, Las mellizas del bardo es arltiana en su moral de lenguaje y en su constitución temática. La zona de clivaje de esta pulp fiction delirante y posapocalíptica es el nudo ciego de épica delictiva, rufianesca y melancólica, negociaciones miserables, manipulaciones grotescas, pasiones genuinas y sublimación resignada que se teje tras el imaginario futbolístico y para-futbolístico. (Crespi, 2013)

En Las mellizas del bardo, la máquina vengadora no es un robot gigante sino el cyborg de Lionel Messi. Recuerda Vanoli sobre la elección de Messi : "No nos olvidemos que Messi es Messi porque se sometió a un tratamiento médico que en Argentina no le quisieron pagar" (Vespa, 2012). El Messi de la novela, "el mismo que nos hizo ganar el mundial 2014 en Brasil [...] el chico bueno al que Pelé y la mafia de las apuestas por internet asesinaron en el aeropuerto de San Pablo", fue transformado luego de morir en un cyborg para que pueda continuar jugando al fútbol. El cyborg es alimentado con la denominada nafta humana a través de "un taponcito blanco que tiene justo en la cintura, entre los dos huequitos que anuncian el culo". La nafta es necesaria para los cyborgs y adictiva para los humanos : "esa que ya de sentirle el olor te lleva a otra galaxia. Ni hablar si le ponés unas gotitas al whisky". Al igual que en El Eternauta de Oesterheld y Solano López y en Embalse de César Aira, el fútbol es el campo de batalla de la ciencia ficción argentina.

28 En el paratexto editorial ubicado en la contratapa puede leerse : "Saqueos en Greiscol es la colección de horror, ciencia ficción, western, fantástico y otros géneros pulp de la editorial Clase Turista". La presencia de géneros masivos, la fijación con el soporte y la utilización del absurdo llevan a preguntarnos por las etiquetas utilizadas por la editorial. Siendo Las mellizas del bardo una publicación de buena calidad de impresión, $i$ es el uso del absurdo lo único que la distingue de Varadero y Habana Maravillosa? En definitiva, ¿ qué es lo que ocurre para que una obra sea publicitada con las etiquetas del género y en otra del mismo autor se las invisibilice? La colección se autodefine como pulp; pese a no estar impresa con la precariedad material que definió al pulp, toma ese nombre por la 
reutilización de los géneros masivos que surgieron bajo ese modo de impresión. Por el contrario, Saqueos en Greiscol posee una calidad de diseño e impresión superior a la de muchas microeditoriales localizadas en Buenos Aires.

29 No es la primera aproximación de Clase Turista al género. Fundada en el 2005 por Iván Moiseeff, Lorena Iglesias y Esteban Castromán, la primera etapa consistió en la publicación de la posteriormente bautizada "Colección Artesanal" : libros-objeto cuya factura remitía al contenido. En su caso más elocuente y ligado con los intereses de este trabajo, el Manual de supervivencia para los días que vendrán fue editado con la portada completamente cubierta de pasto artificial de un par de centímetros de espesor. El Manual ... construye un relato apocalíptico mediante la utilización de otro género, el manual de instrucciones. En una segunda etapa, los editores encargaron a artistas de diversas ramas la creación de las diferentes obras que conforman Mental Movies : imaginar una película ideal y publicar su trama a modo de cuento en el revés del poster de la película, distribuido junto a un cd con una canción que funcione de soundtrack. En el relato escrito por Moiseeff, el robot Mazinger Z de la serie animada japonesa de los setenta combate a la dictadura militar argentina.

La misma intención pulp resurge en El juguete rabioso y radioactivo, de Nicolás Saraintaris. Su sinopsis : "Silvio Astier, joven lector de revistas de ciencia ficción, sueña con escribir sobre civilizaciones extraterrestres y aventuras en el espacio. Pero lo que no se imagina es que en su afán por escapar del aburrimiento de la vida diaria terminará enfrentándose con una serie de monstruos radioactivos producto de las experimentaciones de un científico nazi que migró al país después de la Segunda Guerra Mundial". Saraintaris tiene una larga trayectoria en el género pulp. Junto a su socio F. Martínez Ruppel mantuvieron durante años el blog Literatura Clase B (ahora reconvertido en la página oficial de la editorial) donde el escritor escribía varias sagas de género (ciencia ficción, aventura, fantasy, acción, erótica) que Martínez Ruppel ilustraba. Ya anunciaron Don Segundo Saurio (Don Segundo Sombra + dinosaurios) y Cavernícolas Vampiros. "La idea es hacer varias colecciones -dice Saraintaris-. Esta con la que comenzamos, Clásicos Alternativos, se trata de reversiones de textos fundamentales de la literatura argentina. Pero más adelante queremos publicar obras inéditas de género de otros escritores". En paralelo, se anunció la creación de Zona Pulp, una colección en ebook dirigida por Alejandro Soifer para la ya nombrada InterZona. Su primer título es del propio Saraintaris con ilustraciones de Martínez Ruppel: Mano propia, "una novelette cyberpunk sobre los linchamientos en Portenia".

31 Finalmente, del lado de las (pocas) editoriales que conservan el género, se puede mencionar el caso de ediciones Ayarmanot, dirigida por Laura Ponce, con libros como Piratas genéticos o la reciente Antología Steampunk: cuentos del retrofuturo, que financió a través de la novedosa estrategia virtual del crowdfunding. De esta manera, si bien en términos industriales Ayarmanot y Momofuku se oponen a Random House, en términos de usos del género Momofuku y Random House se oponen a Ayarmanot; bajo estas dos tendencias se publica la ciencia ficción hoy en Argentina.

\section{Conclusiones}

32 El panorama actual presenta una situación de mucha dispersión. Las fronteras del guetto se rompieron, y si bien siguen existiendo bolsones de ciencia ficción "pura", sus contenidos se dispersaron. Esto, si bien mayoritaria, no es un privilegio de la edición 
independiente : hay mucha publicación de ciencia ficción borroneada en los sellos más prestigiosos de los conglomerados multinacionales.

A la línea conformada por Marcelo Cohen, Alberto Laiseca, Angélica Gorodischer o César Aira, hoy se puede agregar una formación completa: Leonardo Oyola, Hernán Vanoli, Federico Falco, Samanta Schweblin, Luciano Lamberti, Carlos Godoy, Nicolás Mavrakis, Sebastián Robles, Pola Oloixarac, Félix Bruzzone, Juan Terranova, Iván Moiseeff, Eric Schierloh, Esteban Castromán, Carlos Ríos, Nicolás Saraintaris, Roque Larraquy, Marcelo Carnero. Cuesta encontrar escritores menores de 40 años que no hayan escrito literatura altamente contaminada por la ciencia ficción, y muchos de los que aún no lo hicieron están en camino, como la prometida novela de Busqued sobre ufología y científicos nazis en la Antártida. En algunos casos, como hizo Rodrigo Fresán con El fondo del cielo, no escriben libros de ciencia ficción sino con ciencia ficción.

Incluso las mejores bandas de la escena indie abrazan el género, como el apocalíptico Día de los muertos de Él mató a un policía motorizado. Editorial Nudista, que publicó varios de los libros de los autores mencionados, también editó un poemario filocientífico, Newton y yo de Marcelo Díaz: "la poesía es un anillo de cenizas / alrededor / de transbordadores espaciales". ¿ Acaso esto no es también ciencia-ficción?

Dos certezas : en primer lugar, la mayoría de las obras de ciencia ficción argentina contemporánea no son catalogadas como ciencia ficción y prefieren ubicarse en el espacio interior antes que en el espacio exterior; en segundo lugar, la mayoría de estas obras no son masivas, sino que preferentemente son publicadas en sellos independientes o en los sellos más prestigiosos y menos comerciales de los grandes conglomerados; incluso cuando se pretenden pulp, no son sino imitaciones de lo pulp; no sólo en su fabricación material, sino en el mercado en donde circulan (el ebook) y las referencias que manejan (la metatextualidad).

36 ¿Están ambas en relación? Posiblemente: mientras que en el fuerte mercado estadounidense la ciencia ficción sigue siendo un género masivo y puede mantener sus viejas formas de circulación (gremios, regalías y premios mediante), en Argentina la publicación ahonda la tendencia europea de abandonar los rótulos en pos de un mayor prestigio literario $\mathrm{y}$, sobre todo, una expansión mayor al gueto del género. Se trata, finalmente, de una ciencia ficción de la truchez, no sólo por su temática (lo precario) sino por su modo de circulación : un género que pierde la marca.

37 Hoy la ciencia ficción argentina renace al abandonar su propio nombre y abrazar la hibridación. ¿Germinará nuevamente la etiqueta o su fusión es un camino sin regreso ? Aunque la etiqueta se pierda, los lectores reconocen sus procedimientos y tópicos, como la extrapolación y la aprehensión de las tecnologías que bordean la comprensión humana; como siempre ha sido, será cuestión de seguir ofreciendo nuevas respuestas para nuevas preguntas. 


\section{BIBLIOGRAFÍA}

Bibliografía

Capanna, Pablo. “Ciencia ficción, siglo XXI : ironía y tecnología de punta”. ADN Cultura. 4 de abril de 2014. http://www.lanacion.com.ar/1678004-ciencia-ficcion-siglo-xxi-ironia-y-tecnologia-depunta

Crespi, Maximiliano. "Cuando Puig se cruza con Arlt”. Revista Ñ. 24 de enero de 2013. http:// www.revistaenie.clarin.com/literatura/resenas/Hernan-Vanoli-Las-mellizas-delbardo_0_850115009.html

Desimone, Facundo (2012). “La experiencia más intensa que tuve con la sociología fue al servicio del mal". The TG Post. 10 de julio de 2013. http://www.thetgpost.com/index.php/libros-y-algomas/libros/19425-hernan-vanoli-la-experiencia-mas-intensa-que-tuve-con-la-sociologia-fue-alservicio-del-mal

Díaz, Marcelo D. Newton y yo. Córdoba : Nudista, 2011.

Enriquez, Mariana. "Plan de evasión". Página/12. 19 de diciembre de 2004. http:// www.pagina12.com.ar/diario/suplementos/libros/10-1361-2004-12-19.html

Gandolfo, Elvio. “La ciencia-ficción argentina”. Los universos vislumbrados (Antología de ciencia ficción argentina), ed Jorge A. Sánchez. Buenos Aires : Andrómeda, 1978.

García, Guillermo. "El otro lado de la ficción : ciencia ficción". Historia crítica de la literatura argentina. Volumen 10 : La irrupción de la crítica, dir. Noé Jitrik y Susana Cella. Buenos Aires : Emecé, 1999. 313-40.

Hacker, Julia. “Interzona Editora presenta su colección 'Línea C' de literatura fantástica”, Interzona, 2004. http://www.interzonaeditora.com/titulos/getAttachment.php?a=30\&f=62

Haraway, Donna : "A cyborg manifesto : science, technology, and socialist-feminism in the late twentieth century". Simians, cyborgs and women : the reinvention of nature. New York : Routledge, 1991.149-181.

Lamberti, Luciano. El loro que podía adivinar el futuro. Córdoba : Editorial Nudista, 2012.

Leonard, Elisabeth Anne. "Race and ethnicity in science fiction". The Cambridge Companion To Science Fiction, ed. Edward James y Farah Mendlesohn. Cambdrige : Cambridge University Press, 2003. 253-263.

Levrero, Mario. La novela luminosa. Buenos Aires : Literatura Random House, 2005.

Lezcano, Walter. “Cómo sumarle al realismo lo fantástico y lo extraño”. Tiempo Argentino. 11 de noviembre de 2012. http://tiempo.infonews.com/nota/15144/como-sumarle-al-realismo-lofantastico-y-lo-extrano

Mavrakis, Nicolás. No alimenten al troll. Buenos Aires : Tamarisco, 2012.

Moiseeff, Iván, Lorena Iglesias y Esteban Casrtomán. Manual de supervivencia para los días del Gran Desastre. Ensayo Post apocalíptico. Buenos Aires : Editorial Clase Turista, 2008.

Pinedo, Rafael. Plop. Buenos Aires : Interzona, 2005. 
Rucker, Rudy. “Cronenberg's NAKED LUNCH as Transreal SF”. Rudy's blog. 25 de enero de 2011. http://www.rudyrucker.com/blog/2011/01/25/cronenbergs-naked-lunch-as-transreal-sf/

Saferstein, Ezequiel y Vanoli, Hernán. "Cultura literaria e industria editorial. Desencuentros, convergencias y preguntas alrededor de la escena de las pequeñas editoriales". 01-10 Creatividad, economía y cultura en la ciudad de Buenos Aires 2001-2010. Buenos Aires : Aurelia Rivero, 2011. 69-100.

Sáliche, Luciano. "Puedo escribir desde la mugre o desde un lugar donde no haya ninguna expectativa”. 30 de marzo de 2014. http://alrededores5.rssing.com/chan-6165493/all_p14.html

Sánchez, Jorge A. (ed). Los universos vislumbrados (Antología de ciencia ficción argentina). Buenos Aires : Andrómeda, 1978.

Szpilbarg, Daniela y Saferstein, Ezequiel. "La independencia en el espacio editorial porteño". Mi Buenos Aires querido. Entre la democratización cultural y la desigualdad educativa. Buenos Aires :

Prometeo, 2012. 221-247

Tomas, Maximiliano. “Un verdadero relato salvaje”. La Nación. 23 de octubre de 2014 http:// www.lanacion.com.ar/1737850-un-verdadero-relato-salvaje

Vanoli, Hernán. Varadero y Habana Maravillosa. Buenos Aires : Tamarisco, 2010.

Vanoli, Hernán. Las mellizas del bardo. Buenos Aires : Clase Turista, 2012.

Vespa, Mariano. “Turismo piquetero”. Revista Tónica. 4 de octubre de 2012. http:// revistatonica.com/2012/10/04/turismo-piquetero/

Wolfe, Gary K. "Science fiction and its editors". The Cambridge Companion To Science Fiction, ed. Edward James y Farah Mendlesohn. Cambridge University Press, 2003. 96-110.

\section{RESÚMENES}

Escribía Elvio Gandolfo en el prólogo de una antología de 1978 : "La ciencia ficción argentina no existe”. Hoy, a razón de una producción novedosa, la ciencia ficción argentina está cerca de tener su propia constelación en el firmamento literario, pero en el tiempo transcurrido tras ese prólogo ocurrieron cambios tanto en el género como en la edición que afectan al modo en el que circula esa producción. A lo largo de este trabajo veremos qué tipo de cambios se produjeron y bajo qué circunstancias de publicación, mediante el análisis de las prácticas editoriales pero también a través de la indispensable y a veces relegada lectura de los textos literarios. Asimismo veremos cómo el peritexto, tanto autoral como editorial, configura los géneros $\mathrm{y}$, en muchos casos, incluso posibilita su surgimiento ; por esta razón se les prestará especial interés.

Dans la préface à une anthologie publiée en 1978, Elvio Gandolfo écrivait : «La science-fiction argentine n'existe pas ». Aujourd'hui, à la lumière d'une production nouvelle, la science-fiction argentine n'est pas loin d'avoir sa propre constellation dans le firmament littéraire. Dans le temps écoulé depuis l'introduction de Gandolfo, des changements concernant non seulement le genre, mais aussi le monde de l'édition argentine ont affecté les façons dont cette production littéraire circule. Dans cet article, nous verrons quels types de changements se sont produits, et sous quelles circonstances de publication. Nous verrons que le péritexte, auctorial comme éditorial, configure les genres et même, souvent, rend possible leur émergence.

In the introduction to a 1978 science fiction anthology, Elvio Gandolfo wrote : "Argentine science fiction does not exist". Today, Argentine science fiction is close to having its own constellation in the literary firmament. In the time elapsed since Gandolfo's introduction, changes have taken place in the genre as well as in the Argentine publishing world, that have affected the ways in 
which that production circulates. In this article, we will try to determine what kinds of changes have occurred in the genre, and in which publishing context. This approach concerns publishing practices but it does not exclude, as it is too often the case, the analysis of literary texts themselves. We will also see how the peritext, authorial and editorial, determines genres and, in many cases, even prompts their emergence.

ÍNDICE

Mots-clés: science-fiction, littérature argentine, pratiques éditoriales

Palabras claves: ciencia ficción, literatura argentina, prácticas editoriales

Keywords: science-fiction, Argentine literature, publishing practices

\section{AUTOR}

\section{MARTÍN FELIPE CASTAGNET}

Universidad Nacional de La Plata 